\title{
Resenha do texto: À sombra de McLuhan, de Andreas Huyssen
}

\section{Summary of text: In The Shadow of McLuhan, by Andreas Huyssen}

\author{
Manoel Deisson Xenofonte Araujo ${ }^{[1]}$
}

O professor de literatura comparada e crítico literário Andreas Huyssen, lançou em 1996 o livro Memórias do modernismo, onde trata de diversas problemáticas dentro do tema da cultura de massa. Dividido em oito capítulos, o autor alemão passeia por discursos diversos, como tecnologia, feminismo, gênero, Pop Art e museologia, inserindo-os dentro do contexto do modernismo e da cultura de massa. Em todos os capítulos, lança novas abordagens críticas sobre os assuntos em questão, sempre contextualizando com teorias e conceitos de autores prévios. A intenção geral do autor transparece ser a de revelar as contradições entre as visões e aspirações modernistas com as reais complexidades da pós-modernidade. O tema também é abordado pelo autor em outras obras como: After the Great Divide: Modernism, Mass Culture, Postmodernism ${ }^{[2]}$, além dos títulos já publicados no Brasil; Culturas do passado-presente: modernismo, artes visuais, politicas da memoria $^{[3]}$ e Seduzidos pela memória ${ }^{[4]}$.

Huyssen segue a corrente teórica foucaultiana sobre a memória e a história, ou seja, age revisando teses e filosofias que a seu ver foram selecionadas e estariam coordenadas
[2] HUYSSEN, Andreas. After the Great Divide. Modernism, Mass Culture, Postmodernism. Bloomington: Indiana University Press, 1986.

[3] HUYSSEN, Andreas. Culturas do passadopresente. Modernismos, artes visuais, políticas da memória. Rio de Janeiro: Contraponto, 2014 .

[4] Seduzidos pela Memória - Arquitetura, Monumentos,. Mídia. Rio de Janeiro: Aeroplano, 2000. 
por determinado sistema de poder. Em entrevista ele detalha suas influências literárias:

Não tínhamos desistido da hermenêutica crítica e tentámos repensar o marxismo cultural da Escola de Frankfurt. Isso não era muito popular na altura, porque o pós-estruturalismo era psicanalítico, semiótico, desconstrutivista, mas não era histórico. Isto só mudou com o cada vez maior impacto do trabalho de Foucault. Foucault trouxe a História de volta ao discurso pós-estruturalista de formas importantes, embora nem sempre do agrado dos historiadores. De qualquer forma, eu acredito que a História, enquanto historiografia, e a memória não são por si opostas uma à outra, e que elas podem trabalhar juntas de forma produtiva, tanto na instrução secundária e no saber, como em instituições como o museu, que têm uma função pública importante a desempenhar na educação enquanto processo de compreensão. Especialmente os museus de arte e de história, que estão na fronteira entre a historiografia e as narrativas da memória. E hoje, tanto a historiografia como os museus desenvolveram uma compreensão muito melhor do seu papel na construção de narrativas, mais do que acontecia no passado. (MAURÍCIO, 2009 P. 143-144)

Na presente resenha, tratarei apenas do capítulo 03, intitulado À sombra de McLuhan, onde o autor estabelece uma análise comparativa entre as teorias sobre a mídia desenvolvidas por Jean Baudrillard e Marshal McLuhan, relacionando o aspecto sócio histórico de ambos.

Huyssen inicia o capítulo apresentando e contextualizando os dois autores supracitados; Marshal McLuhan, célebre teórico da comunicação canadense tratava sobre as transformações sociais provocadas pela revolução tecnológica do computador e das telecomunicações nos anos 60 , enquanto o sociólogo francês Jean Baudrillard questionava nos anos 80 a massificação crítica provocada por estes mesmos meios.

Cabe aqui ressaltar que Baudrillard desenvolveu ao longo de sua vida uma vasta série de teorias sobre a dominação do sistema de signos contemporâneos sobre o homem. Com um discurso geralmente irônico e apocalíptico, este pensador pregava a ideia de que a humanidade vive sob uma realidade construída e imposta pela mídia e a tecnologia. Vale 
destacar que, em contraste com Huyssen, era um anti-foucaultiano declarado. Destaco aqui um trecho do seu livro; Esquecer Foucault:

(...) tudo isso se lê diretamente no discurso de Foucault (que É também um discurso de poder): ele escorre, penetra e satura todo o espaço que abre, os menores qualificativos vão-se imiscuir nos menores interstícios do sentido, as proposições e os capítulos se enrolam em espiral, uma arte magistral do descentramento permite que se abram novos espaços (espaços de poder, espaços de discurso) que são imediatamente obturados pelo desenvolvimento minucioso da sua escrita. Não há vazios em Foucault, nem fantasmas, nem contracorrentes: uma objetividade fluente, numa escrita não-linear, orbital, sem falhas, $O$ sentido não excede nunca o que é dito: nada de vertigens; em compensação não voa nunca num texto demasiado grande para ele: nada de retórica. Enfim, o discurso de Foucault é um espelho dos poderes que ele descreve (BAUDRILLARD, 1984 p. 11-13)

Dentre o vasto arcabouço teórico de Baudrillard, Huyssen enfoca principalmente a chamada Teoria da simulação e do simulacro, ilustrando esta ideia através da narração de uma experiência pessoal: O autor relata ter visto um cartaz anunciando uma palestra de Jean Baudrillard com lotação esgotada, a qual aparentemente nunca aconteceu e nem mesmo foi posta à venda de ingressos. A palestra, nos olhos do Huyssen, seria então a representação do próprio simulacro da teoria da hiper-realidade baudrillardiana, ou seja, uma simulação da realidade, que para fins de efeito gera mais atrativos do que a própria realidade. Cabe aqui ressaltar que a escrita de Huyssen, apesar de densa em conteúdo, é rica em certo coloquialismo, o que lhe confere a liberdade de expressar opiniões e experiências pessoais sem lhe requerer o formalismo de uma linguagem mais científica.

Huyssen segue então descrevendo os principais estudos de Baudrillard que enfocam o tema mídia e cultura de massa, assim como suas ramificações e influências. Na busca por origens conceituais da tese baudrillardiana é que o autor chega a McLuhan, alegando haver uma intertextualidade nos trabaIhos do primeiro com os do segundo. Esta afirmação fica mui- 
to mais contundente com a revelação do fato de que, o então jovem Baudrillard, teria resenhando uma obra de McLuhan nos anos 60. Mais interessante no entanto é forma em que Huyssen ilustra o contexto socio-historico de ambos autores. Neste sentido é perceptível que o objetivo do autor é relacionar a presença de um certo otimismo sobre as mídias preponderante nos anos 60 e defendido por McLuhan, com um certo cinismo nos anos 80 exaltado por Baudrillard.

Tanto McLuhan quanto Baudrillard nadaram contra a corrente ideológica dos intelectuais que vigoravam em sua época. McLuhan combatia a hostilidade dos tradicionais humanistas frente à mídia e a modernização enquanto que Baudrillard atacava o discurso marxista ocidental clássico, utilizando-se das teorias da semiologia como armas e barricadas. Se em McLuhan é perceptível o reflexo da euforia popular diante dos meios de comunicação modernos, em Baudrillard se vê o cinismo dominante do período pós-anos 60, perspectiva esta que já havia sido diagnosticado por Peter Sloterdijk em Critique of Cynical Reason ${ }^{[5]}$ (HUYSSEN, 1996).

A análise comparativa das teorias e dos autores não é o ponto final do trabalho de Huyssen, o qual lança uma nova reflexão sobre o tema em questão, demonstrando pontualmente os aspectos em que as teorias de ambos os autores se diluem com a pós-modernidade: Em McLuhan temos o exemplo do conceito de meios quentes e frios, derivados da teoria da Aldeia Global, que seria o estágio da história cultural onde estaria inserido a época do autor. Neste sentido uma sociedade fria seria relacionada a uma característica moderna e uma experiência de impacto mais individualista, enquanto que uma sociedade quente seria relacionada a uma característica primitiva e uma experiência de impacto mais coletivo. Estas definições tornam-se na contemporaneidade bastante difíceis de serem aplicadas na classificação das diversas mídias digitais hoje disponíveis. À sua época, por exemplo, McLuhan classificou a TV como um meio quente, algo que é questionável tendo em vista os vários formatos, funções e definições de
[5] SLOTERDIJK, Peter. Critique of the Cynical Reason. Minneapolis: The University of Minessota Press, 2010. 
tela dos aparelhos atuais. A própria interpretação mcluhiana de que o meio é a mensagem torna-se também um tanto quanto refutável ao se negligenciar os conteúdos de tais meios.

Sobre Baudrillard, Huyssen alega que a teoria da simulação e da Hiper-realidade foi elevada a um nível de generalização tal que beira o absurdo. Sob a compreensão do autor, a única maneira de perceber a realidade fora da simulação descrita por Baudrillard seria a partir dos olhos de Deus. Huyssen também critica o conceito de hiperconformismo, segundo o qual a sociedade seria apenas uma massa receptora das imagens disseminadas pela mídia, independente do contexto cultural ou temporal em que esta se inscreve. A adoção do termo hiperconformismo seria então um recurso de Baudrillard para evitar as palavras Reificação e Alienação, comumente utilizadas nas teorias situacionistas como em Society of spetacle ${ }^{[6]}$ de Guy Debord. Dessa forma Baudrillard não daria margem para contradições ou contra-argumentos possíveis para estes termos. O hiperconformismo seria então um discurso com uma abrangência absurdamente irrefutável tal qual a hiper-realidade.

Neste sentido Huyssen prossegue fazendo a crítica mais mordaz a Baudrillard. Segundo ele ao tratar a mídia de forma holística, como sendo uma única "persona", ou seja, uma mesma engrenagem monolítica de disseminação de conteúdo, Baudrillard está omitindo a possibilidade de uma análise mais profunda sobre a mídia enquanto veículo de ideologia. Nas palavras do autor, Baudrillard não oferece nada além de "uma gratificação intelectual momentânea aqueles que não estão interessados em entender a mídia". (HUYSSEN, 1996, p. 75)

Por fim ele conclui então sua análise com uma reflexão poética e bem humorada sobre a existência real de uma possibilidade de escape da hiper-realidade, relacionando a teoria do simulacro com um buraco negro, implacável e inescapável sob quaisquer referentes em que se apresente em determinado espaço e tempo.

Lanço agora algumas reflexões possíveis neste ensaio de Andresa Huyssen: A leitura da Huyssen hoje traz á tona a
[6] DEBORD, G. A sociedade do espetáculo. Rio de Janeiro: Contraponto, 1997. 
percepção da incrível dinâmica dos meios midiáticos da pós-modernidade. Neste sentido é interessante perceber que, se este autor já lançava uma reflexão sobre a validade das teorias de Baudrillard e de McLuhan no contexto da década de 90 (a data da publicação é de 1996), podemos então refletir em quais pontos tais teorias se tornam mais distantes da realidade dos dias atuais, onde a mídia digital se ramificou em uma multiplicidade de meios tecnológicos como celulares, tablets, notebooks, smartwaches etc.

Podemos por exemplo imaginar um diálogo entre Baudrillard e McLuhan sobre o que pensam sobre o YouTube ${ }^{[7]}$, a plataforma digital de vídeos que concretizou o vislumbre da celebridade instantânea preconizada por Andy Warhol, (artista que coincidentemente é tratado em outro capítulo do livro de Huyssen) o qual afirmava que no futuro todos teriam seus quinze minutos de fama.

É possível ainda indagar se McLuhan enfatizaria ainda mais sua máxima de que o meio é a mensagem, utilizando-se como exemplo o fato da existência de diferentes conteúdos de informação em redes sociais com características similares, tais quais Facebook ${ }^{[8]}$, Tumb/r ${ }^{[9]}$, Myspace ${ }^{[10]}$, Twitter ${ }^{[11]}$, Instagram $^{[12]}$ etc. Aqui daríamos créditos para este célebre comunicólogo, visto ser possível a comprovação de que o meio em questão (a rede social) parece realmente ser por vezes mais incisivo do que o próprio conteúdo. Lógico que aqui estamos [8] https://facebook.com/

[7] https://youtube.com/

[9] https://tumblr.com/

[10] https://myspace.com/

[11] https://twitter.com/

[12] https://instagram.com/ tratando apenas de um aforismo da máxima mcluhiana, muito bem elucidado por Braga (2012):

O sentido deste aforismo é de que um meio transforma o seu conteúdo: um mesmo filme exibido na TV ou no cinema, por exemplo, resulta em experiências bastante diferentes para quem assiste. 0 mal-estar recorrente de espectadores/as frente a adaptações literárias para o cinema ou versões em livro de filmes consagrados é outro exemplo. O que este segundo sentido salienta é, portanto, que cada tecnologia traz consigo um bias (para usar o termo de Harold Innis, mentor de McLuhan), que condiciona o sentido do que é transmitido por meio dele. E este condicionamento do sentido faz com que cada meio seja, ele mesmo, parte do campo significante. (BRAGA, 2012) 
Por outro lado, penso que Baudrillard reveria sua reflexão sobre a manipulação midiática: Ao perceber a aparente autonomia de escolha de conteúdo na web, o autor provavelmente acusaria o Google ${ }^{[13]}$ de uma manipulação subliminar, sutil e personalizada. Baudrillard desconfiaria dos anúncios que pululam em janelas pop up ${ }^{[14]}$ com produtos que aparentemente condizem com a personalidade do usuário. Numa revisão de sua própria bibliografia diria então que a mídia não é mais monolítica e auto-gerada, mas é gerada para você e por você. Isso no entanto não implicaria dizer que não se trata ainda de uma manipulação.

Ouso ainda imaginar o que ambos os autores pensariam sobre o WhatsApp ${ }^{[15]}$ ao se depararem com um casal em um restaurante absortos cada qual em seu smartphone: McLuhan se preocuparia em classificar este complexo meio, chegando talvez na conclusão de que não seria nem quente nem frio, mas morno. Baudrillard por sua vez veria o ápice da hiper-realidade, a qual absorveria a humanidade de tal forma que a interação física ficaria subpujada. É claro que a mente destes gênios não trabalharia de forma tão simplória assim. Faço este exercício mental um tanto quanto lúdico apenas para ilustrar a complexidade de um estudo sobre os meios midiáticos contemporâneos. Neste sentido é Interessante notar que a antropologia parece ser atualmente a ciência mais prolífera nos estudos destas novas mídias "personalizadas". Nadando contra o pensamento generalizador de Baudrillard, a visão antropológica pode oferecer mais que "uma gratificação intelectual momentânea aqueles que não estão interessados em entender a mídia" (HUYSSEN, 1996, p. 75).

Como conclusão chamo a atenção para um detalhe observado na leitura de Huyssen: Penso que o tema geral sobressaído nesta obra, assim como em outras obras supracitadas do autor é o tempo. O tempo e suas ações sobre as teorias e filosofias... a previsão do futuro e a revisão do passado... a complexidade das teorias de um passado mais simples com a simplicidade das teorias em um presente complexo. Após a leitura ficamos imaginando o quão resilientes ou efêmeras serão as filosofias políticas e lutas em vigor.
[13] https://google.com/

[14] Janelas que abrem de forma não intencional quando se acessa determinadas páginas da internet.

[15] https://whatsapp.com/ 


\section{REFERÊNCIAS}

BAUDRILLARD, Jean. Esquecer Foucault, Trad, Cláudio Mesquita e Herbert Daniel, Rio de Janeiro, Rocco,1984. 99 p.

BRAGA, A. McLuhan entre conceitos e aforismos.

Alceu (PUCRJ), v. 12, n.24, p. 48-56, 2012.

HUYSSEN, Andreas. Memórias do modernismo. tradução de Patrícia Faria. Rio de Janeiro: Editora UFRJ, 1996.

MAURício, Ana Fabíola. Entrevista a Andreas Huyssen. Revista Comunicação \& Cultura (Universidade Católica Portuguesa), n. ${ }^{\circ}$ 7, 2009, pp. 141-151 